\title{
Precipitation and temperature regulate the seasonal changes of NDVI across the Tibetan Plateau
}

\author{
Jian Sun ${ }^{1} \cdot$ Xiaojing Qin ${ }^{2}$
}

Received: 11 February 2015/Accepted: 19 October 2015/Published online: 10 February 2016

(C) Springer-Verlag Berlin Heidelberg 2016

\begin{abstract}
The spatiotemporal variability of the seasonal dynamics of the climate and vegetation index was analyzed, and the relationship between the vegetation index and various climate factors were explored (1982-2013) across the Tibetan Plateau. Severe variations in mean temperature, accumulated precipitation, and the normalized difference vegetation index (NDVI) were observed in the spring, summer, autumn, and winter. It found that the maximum NDVI of the study area increased at rates of $0.5 \%$ per 10 years for spring (March-May), $0.4 \%$ per 10 years for summer (June-August), $1.3 \%$ per 10 years for autumn (September-November), and $0.3 \%$ per 10 years for winter (December-February). Moreover, the change trends for temperature and precipitation increased as a whole. We demonstrated the correlation among NDVI and mean temperature and accumulated precipitation, in season, with the results differing for each season.
\end{abstract}

Keywords Tibetan Plateau - Normalized - Difference vegetation index $\cdot$ Temperature $\cdot$ Precipitation $\cdot$ Seasonal variation

Jian Sun

sunjian@igsnrr.ac.cn

Xiaojing Qin

xiaojingqin513@163.com

1 Synthesis Research Centre of Chinese Ecosystem Research Network, Key Laboratory of Ecosystem Network Observation and Modelling, Institute of Geographic Sciences and Natural Resources Research, Chinese Academy of Sciences, Beijing, China

2 Institute of Land and Resources, China West Normal University, Nanchong, China

\section{Introduction}

The climate has warmed by approximately $0.68^{\circ}$ over the past 100 years (Walther et al. 2002), which has significantly affected ecosystems in many regions (Wang et al. 2007). Vegetation on land surfaces is not only the first layer of information that remote sensing collects; it also collects important information for studying plant growth (Gurgel and Ferreira 2003). The most widely used vegetation index is the normalized difference vegetation index (NDVI), which is a good indicator of large-scale vegetation cover and vegetation productivity. One of the objectives in remote sensing studies is to explore how vegetation cover responds to climate changes (Schultz and Halpert 1995). It is well known that climate and environment have an interactive relationship. Thus, many research studies have focused on the relationship between NDVI and climatic factors at the regional and global scale (Liu and Chen 2000). The Tibetan Plateau, known as the "world's third pole," is extremely sensitive to global changes. The alpine grassland on the Tibetan Plateau has an important function in the global carbon cycle. Thus, it provides an ideal area to study the interaction between climate and vegetation cover due to the complicated climate regime as well as a low population density and limited human activities on the Tibetan Plateau. Therefore, it is useful to research the spatiotemporal changes of vegetation and climate across the Tibetan Plateau.

Many studies have examined the relationship between NDVI distribution and different environmental factors. A significant warming trend has been reported for the Tibetan Plateau since the mid-1950s (Fan et al. 2010), and climate warming is supposed to be the main cause of increased grassland yield in this region (Wang et al. 2008). In the southwestern region of China, the variation in annual mean 
temperature surpasses precipitation in affecting vegetation dynamics (Ji and Peters 2004). In contract, in grassland and cropland, water balance accounts for $46 \%$ of the NDVI variation (Chu et al. 2007). Moreover, climate response analyses have shown that NDVI values are more sensitive to precipitation variations than to temperature variations in the Lhasa area (Peng et al. 2010), and that precipitation was the most important factor influencing tree growth in the northeastern Tibetan Plateau (Gao et al. 2010). For example, the recovery and protection of alpine grasslands benefited from precipitation variation in these regions. Some studies have even indicated that the impact of regional climate change on alpine grassland net primary productivity was more detrimental overall than advantageous (Revadekar et al. 2012). In fact, in terms of climatic factors, precipitation and temperature serve as important environmental factors that affect plant growth and distribution (Wang and French 1994).

In summary, climatic factors play an important role in the NDVI of the Tibetan Plateau. However, few studies have focused attention on the variety of seasonal climatic factors and the relationship with NDVI in the four seasons. The objectives of this paper are: (1) to analyze the temporal patterns of temperature and precipitation in the different seasons; (2) to identify the spatial and temporal patterns of NDVI variability in the different seasons; and (3) to diagnose the characteristics of vegetation that changed in accordance with temperature and precipitation in the different seasons.

\section{Materials and methods}

\section{Study area}

The Tibetan Plateau $\left(80^{\circ}-105^{\circ} \mathrm{E}, 27^{\circ}-37^{\circ} \mathrm{N}\right)$, located in southwest inland China (Fig. 1), is the highest and most extensive plateau in the world; is it also known as the roof of the world (Fan et al. 2010), and it is surrounded by the Earth's highest mountains, including the Himalayas, Pamir, and Kunlun Shan. The plateau has a cold and dry climate (Sun et al. 2002). A gigantic tectonic geomorphologic region of Earth, the Tibetan Plateau has experienced remarkable climate change, which has had a serious impact on the alpine grassland ecosystem in recent years (Gao et al. 2009).

\section{Date and statistical methods}

We collected meteorological date from 127 meteorological observatories around and on the Tibetan Plateau in our study (Fig. 1). Climatic data were downloaded from the
Meteorology Information Center of the Chinese National Bureau of Meteorology (China Meteorological Data Sharing Service. Available online: http://cdc.cma.gov.cn/ [accessed on 20 August 2014]) and included seasonal mean temperature (SMT) and seasonal accumulated precipitation (SAP).

The NDVI data were derived from global inventory monitoring and modeling studies (GIMMS) from 1982 to 2013, and a working group provided the third generation of NOAA/AVHRR remote sensing data (NDVI3g), which are composited from 15 days of data using the maximum value composite (MVC) method (Sun et al. 2013). Improved results are obtained by eliminating the effects of geometry, clouds, aerosols, and other factors on the actual vegetation changes. In addition, the native resolution of the remote sensing products is $0.083^{\circ}$.

As previously mentioned, the daily climatic data from different meteorological stations were presented in a monthly format. Interpolations were made using these points as coordinate and climatic data on the Tibetan Plateau project map via Universal Kriging methodology. The GIMMS NDVI3g and climate factors were analyzed at $0.25^{\circ}$ spatial resolution for 1982-2013.

For this study, we took the time series of maximum value of NDVI for the three months of each season for processing, using MVC methods to remove the remaining noise from satellite-borne data sources in the NDVI time series (Sun et al. 2013). As we divided the time series into four seasons [spring (March-May); summer (June-August); autumn (September-November); and winter (December-February)] in order to study them more closely, we calculated the rate of change for each season from 1982 to 2013 using the following formula (Xu et al. 2008):

$\mathrm{SLOPE}=\frac{n \times \sum_{i=1}^{n} i \times \mathrm{MNDVI}_{i}-\sum_{i=1}^{n} i \times \sum_{i=1}^{n} \mathrm{MNDVI}_{i}}{n \times \sum_{i=1}^{n} i^{2}-\left(\sum_{i=1}^{n} i\right)^{2}}$,

where $n$ is the natural number, such as $1,2,3, \ldots, n$ beginning with 1982, and $\mathrm{MNDVI}_{i}$ is the maximum value of NDVI for each season in year $i$.

On the one hand, SLOPE refers to the index of the degree of change in vegetation, and the amplitude of the changed vegetation index can be represented by the word RANGE, as demonstrated below. Moreover, in this study, we use PERCENTAGE to identify the percentage changes (Sun et al. 2013):

RANGE $=$ SLOPE $\times(n-1)$

PERCENTAGE $=\frac{\text { RANGE }}{\left(\frac{\sum_{i=1}^{n} \mathrm{MNDVI}_{i}}{n}\right)} \times 100$. 


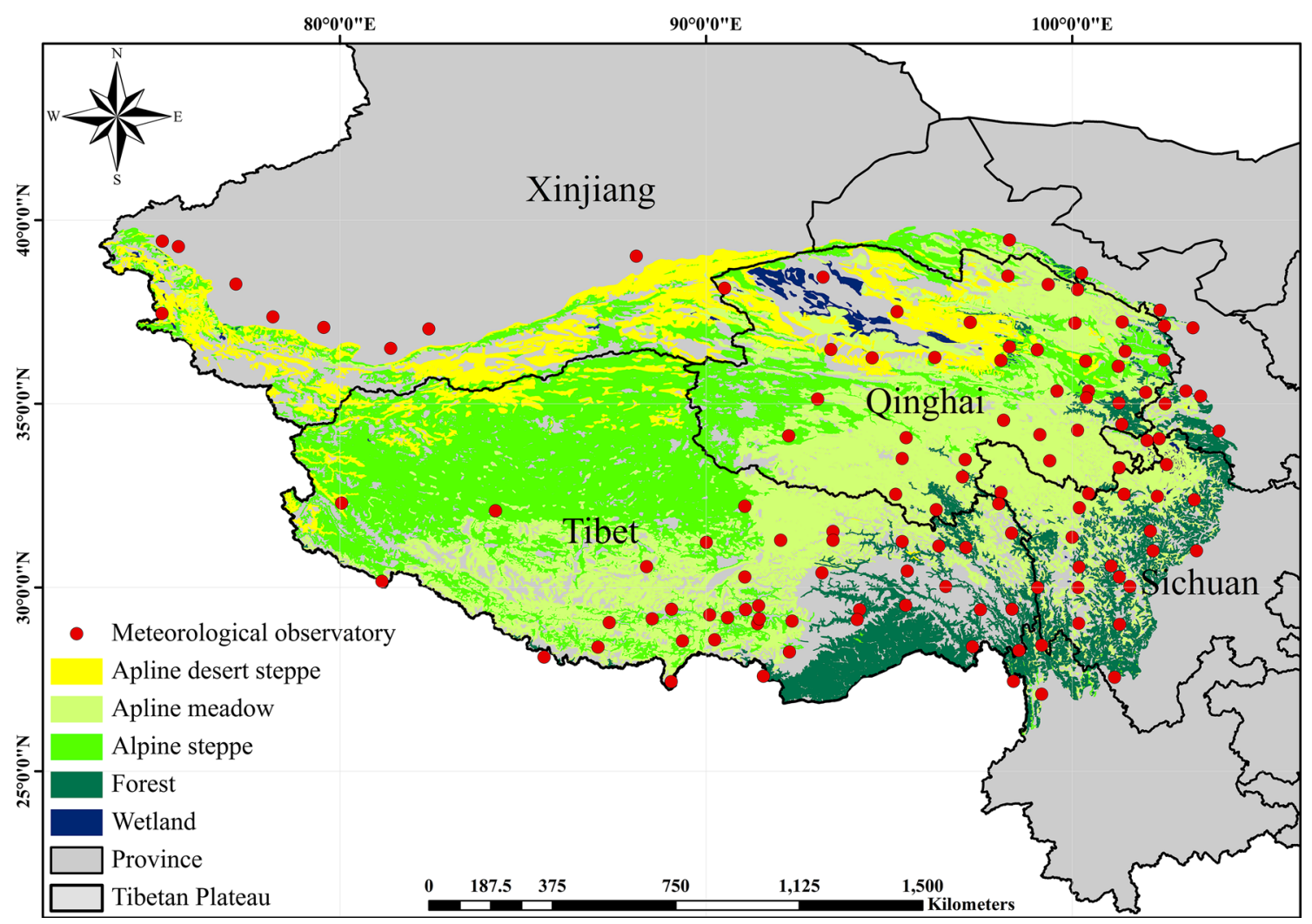

Fig. 1 Distribution of meteorological stations across the Tibetan Plateau

On the other hand, Pearson indicates the size of data correlation measurements between two groups obtaining magnitude and direction. Moreover, the greater the absolute value of the figure, the greater the strength of the correlation of two variables (Revadekar et al. 2012):

$R_{x y}=\frac{\sum_{i=1}^{n}\left[\left(x_{i}-\bar{X}\right) \times\left(y_{i}-\bar{Y}\right)\right]}{\sqrt{\sum_{i=1}^{n}\left(x_{i}-\bar{X}\right)^{2} \times \sum_{i=1}^{n}\left(y_{i}-\bar{Y}\right)^{2}}}$,

where $R_{x y}$ is the correlation index between NDVI and climatic factors; $x_{i}$ is the MNDVI value of the season in $i$ year; $\bar{X}$ is the average MNDVI value in one season from 1982 to 2013; $y_{i}$ is the climatic factor value of the season in $i$ year; and $\bar{Y}$ is the average climatic factor value in one season from 1982 to 2013.

In addition, the autoregressive integrated moving average (ARIMA) model was used in this paper to analyze the temporal trend of NDVI, temperature, and precipitation (R, "forecast" package). Moreover, the data used in this study were analyzed using ArcGIS 9.3 (ESRI, Inc., Redlands, CA, USA), SigmaPlot for Windows version 10.0 (Systat Software, Inc., Chicago, IL, USA), and R software (R Development Core Team 2011).

\section{Results}

\section{Spatiotemporal changes of NDVI in the different seasons}

The study used the maximum NDVI of the 3 months of each season as a representative value. Figure 2 shows a seasonal variability of NDVI from 1982 to 2013. There was an increasing trend in NDVI over the past 32 years except in winter. The mean values of NDVI are $0.17,0.32,0.24$, and 0.15 in the spring, summer, autumn, and winter, respectively. Seasonal comparison revealed the largest change rate to be for autumn with 1.30 per 10 years (Fig. 2c), and the smallest change ratio in winter with 0.30 per 10 years (Fig. 2d). In the summer, NDVI varied from 0.30 to 0.34 , with a minimum of 0.30 in 2012 and a maximum of 0.34 in 2000 (Fig. 2b). Meanwhile, the NDVI in all seasons are insignificantly changed with time series $(p>0.05)$, and all the predicted values of NDVI present gentle trends.

Seven levels were applied in order to demonstrated the trend change of NDVI (Table 1); the trend slopes of NDVI are shown in Fig. 3. No changed trends were detected in 

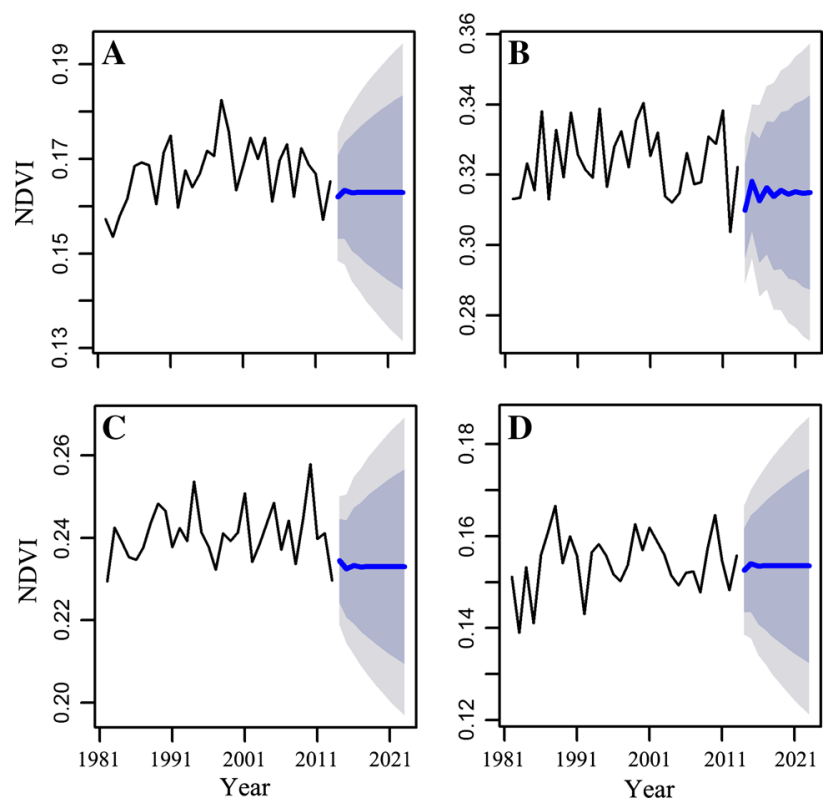

Fig. 2 Temporal trends of NDVI from 1982 to 2013. Graphs a, b, c, and $\mathbf{d}$ represent variations of NDVI in the spring, summer, autumn and winter, respectively

most of the observatory stations and the significant recovery region located in eastern and southern Tibetan Plateau. Meanwhile, the similarly changed regions were found in different seasons from 1982 to 2013. Figure 4a shows that significant recovery occurred in the eastern Tibetan Plateau, with the percentage varying from 40 to $75 \%$. In the spring, vegetation in most areas of the Tibetan Plateau did not undergo changes with large fluctuations, with percentages varying from -41 to $10 \%$. However, in the summer, most regions experienced an insignificant recovery level, with the percentage of 10 to $40 \%$. Based on Figs. 3 and 4c, the area of significant recovery expanded on the eastern Tibetan Plateau. Figure $3 d$ suggests that the significant degradation phenomenon was worse in winter than in other seasons, and nearly all of the percentage change values ranged from -40 to $10 \%$ in Fig. $4 d$.

\section{Temporal changes of temperature and precipitation in different seasons}

Variations of the seasonal temperature (SMT) and seasonal precipitation (SAP) across the Tibetan Plateau from 1982 to 2013 were explored (Figs. 5, 6), and the average SMT value was $4.78,14.00,4.28$, and $-6.53{ }^{\circ} \mathrm{C}$ in spring, summer, autumn, and winter, respectively. SMT increased by $0.60,0.53,0.50$, and $0.68{ }^{\circ} \mathrm{C}$ per 10 years in the spring, summer, autumn, and winter, respectively. From the data previously analyzed, the warming trend was greater in the cold season than in the warm season. Furthermore, the temperature increased $0.53{ }^{\circ} \mathrm{C}$ from the lowest to highest value in the winter in the past 32 years. Meanwhile, the temperature in the spring (Fig. 5a), summer (Fig. 5b), autumn (Fig. 5c), and winter (Fig. 5d) are significantly changed with time series $(p<0.01)$, the $R$ square values are $0.745,0.865,0.704$, and 0.651 , respectively. However, the all seasonal predicted values present gentle trends.

The variation of the precipitation (Fig. 6) has no significant change in autumn (Fig. 6c) and winter (Fig. 6d). The mean values of seasonal precipitation were $57.95 \mathrm{~mm}$ and $207.80 \mathrm{~mm}$ in spring (Fig. 6a) and summer (Fig. 6b) from 1982 to 2013, respectively. The precipitation in spring and summer is significantly changed with time series $(p<0.05$ ); the $R$ square values are 0.554 and 0.353 , respectively. In addition, the predicted value of spring precipitation presents increased trends. By contrast, the precipitation was mainly concentrated in the summer, which experienced approximately $60 \%$ of annual precipitation. This finding suggests that approximately $90 \%$ of the annual precipitation is concentrated in the months of May to September.

\section{Relationship between seasonal NDVI and temperature/precipitation}

Figure 7 shows that seasonal NDVI on the Tibetan Plateau is positively correlated with temperature. Basically, in
Table 1 Classified result of maximum normalized difference vegetation index (MNDVI) change simulated from 1982 to 2013

\begin{tabular}{lll}
\hline Items & The trend of MNDVI change & Status \\
\hline Category & Slope $\leq-0.0091$ & Extremely significant degradation \\
& $-0.0091 \leq$ Slope $\leq-0.0046$ & Significant degradation \\
& $-0.0045 \leq$ Slope $\leq-0.0010$ & Insignificant degradation \\
& $-0.0009 \leq$ Slope $\leq 0.0009$ & No change \\
$0.0010 \leq$ Slope $\leq 0.0045$ & Insignificant recovery \\
$0.0046 \leq$ Slope $\leq 0.0090$ & Significant recovery \\
Slope $\geq 0.0090$ & Extremely significant recovery
\end{tabular}




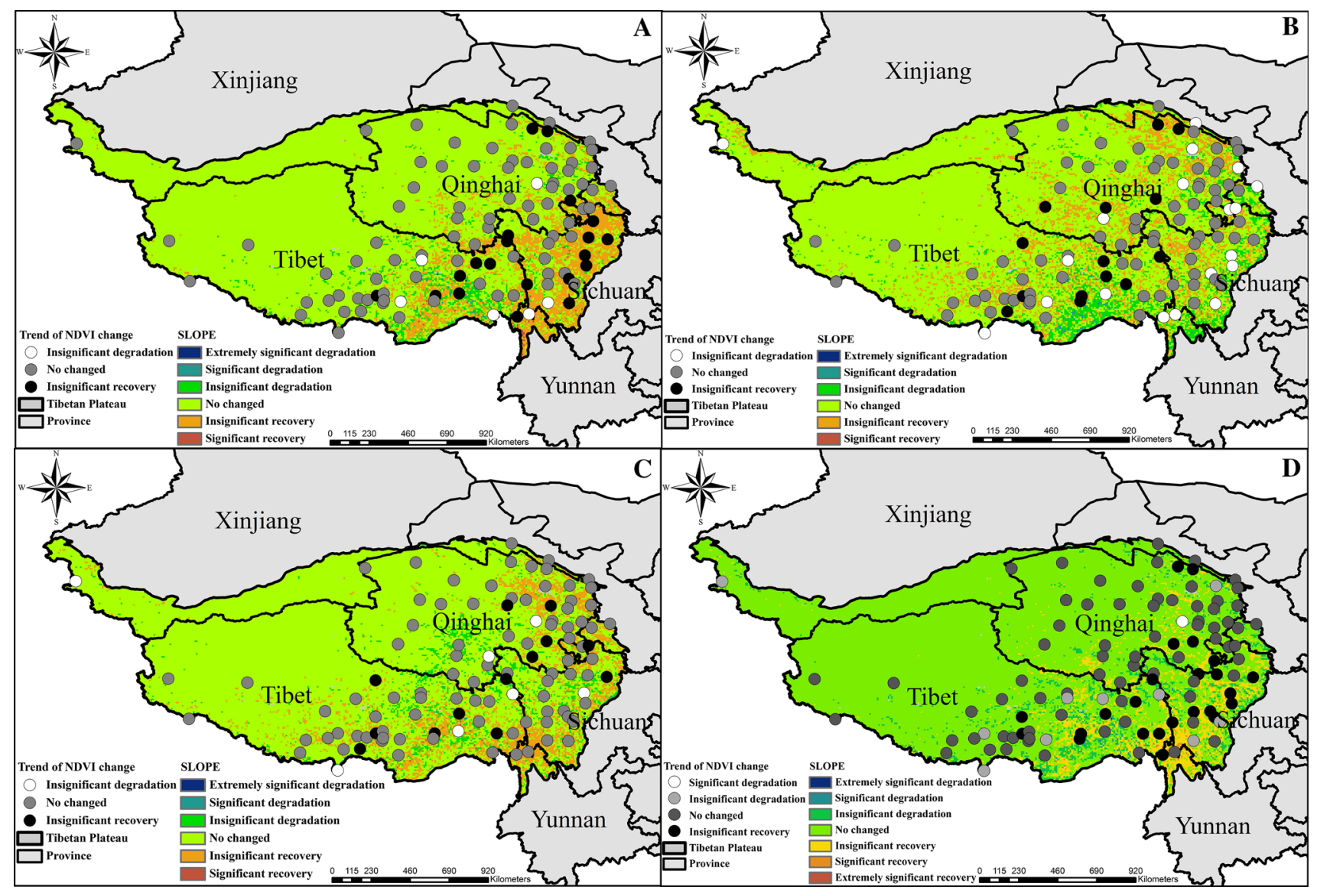

Fig. 3 Change slope of NDVI on the Tibetan Plateau from 1982 to 2013. Graphs $\mathbf{a}, \mathbf{b}$, $\mathbf{c}$, and $\mathbf{d}$ represent variations of NDVI in spring, summer, autumn, and winter, respectively. Solid circles represent the slopes of all observatory stations

Sichuan sections, NDVI and temperature appear to have had a significantly positive correlation in the spring (Fig. 7a), gradually weakening in autumn (Fig. 7c) and winter (Fig. 7d). A slight negative correlation between NDVI and temperature was found in southern Tibet, especially in the summer (Fig. 7b). Nevertheless, in the northeastern Tibetan Plateau, negative correlation is shown, except in the winter. Moreover, the correlation has been stronger in the spring and summer than in the autumn and winter. In summary, areas that have a positive correlation were larger than the negative correlation areas on the whole Tibetan Plateau.

By contrast, the correlation between NDVI and precipitation is not the same as between NDVI and temperature (Fig. 8). The significant positive correlation occurs in eastern Qinghai in the spring, which clearly differs from other places in cold regions. In the summer (Fig. 8b), positive correlation occurs in southern Tibet and northern Qinghai. Nearly most of the Tibetan Plateau appeared in the negative correlation, except in the summer.

\section{Discussions}

\section{Spatiotemporal changes of NDVI}

The seasonal dynamics are represented in the NDVI variations (Fig. 2). From the early 1980s to 2000, vegetation cover shows a rising trend on the Tibetan Plateau (Liu et al. 2008). Most regions of the Tibetan Plateau present recovery trends in the spring and autumn but degradation trends in the summer and winter. The above results were verified in another study, which found that, in the Lhasa area, the NDVI achieves its peak point in July or August and its low point in March and April (Peng et al. 2010). Although in the Three Rivers Headwaters Regions of the Tibetan Plateau, the grassland yield has increased a little from 1988 to 2005; it is not to rule out the possibility that grazing pressures have a negative impact on the restoration of grassland ecosystems (Wang et al. 2008). Moreover, the alpine meadow of the Tibetan Plateau presented degradation to a certain extent (Wang et al. 2007). In summary, in terms of vegetation cover, the conditions of change were different at different seasons. 


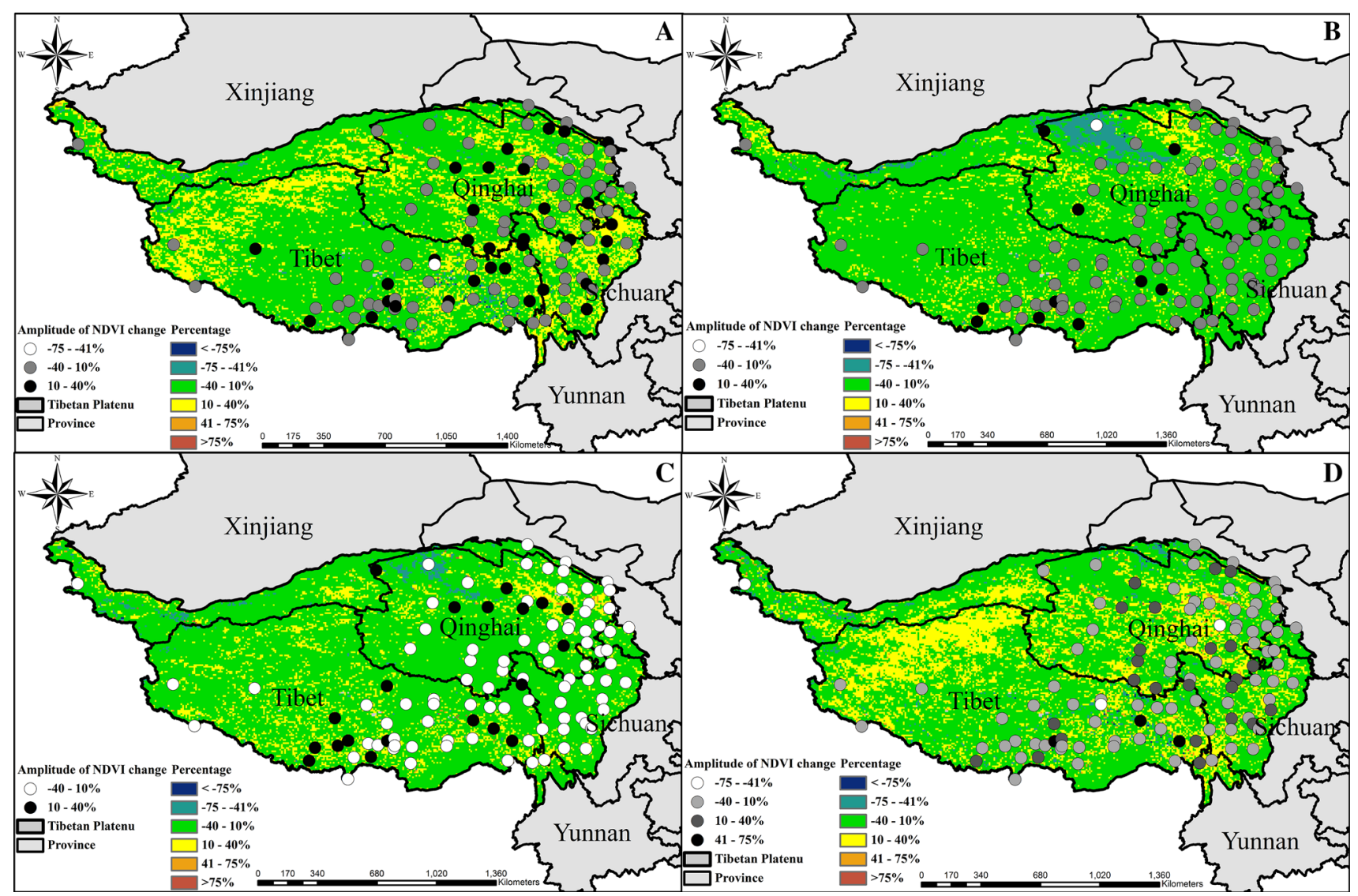

Fig. 4 Amplitude of variation of NDVI on the Tibetan Plateau from 1982 to 2013. Graphs a, b, c, and d represent variations of NDVI in spring, summer, autumn, and winter, respectively. Solid circles represent the amplitudes of all observatory stations
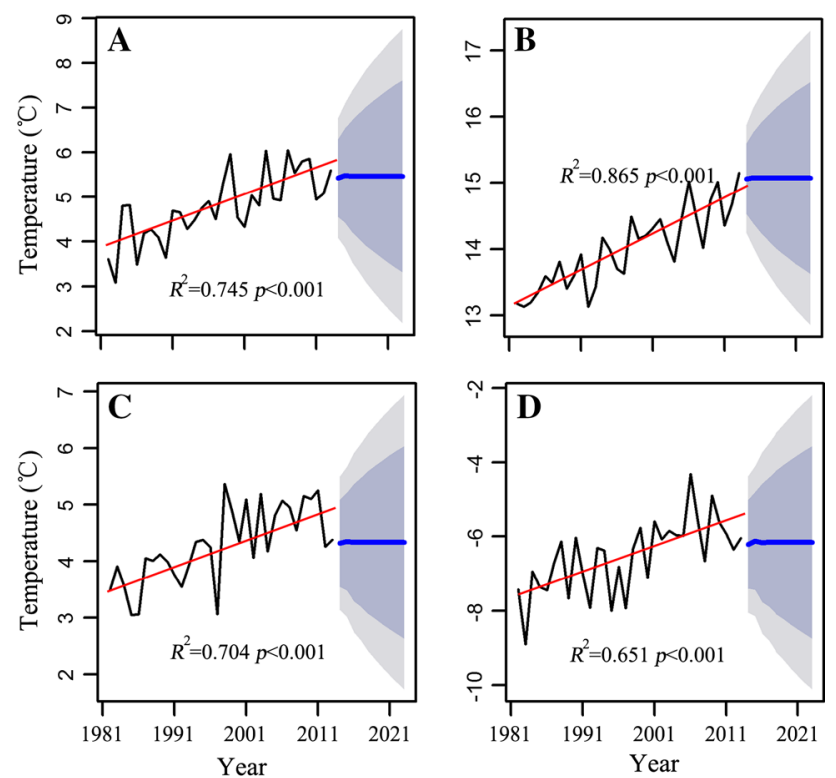

Fig. 5 Variations in temperature on the Tibetan Plateau from 1982 to 2013. Graphs a, b, c, and d represent variations of temperature in spring, summer, autumn, and winter, respectively
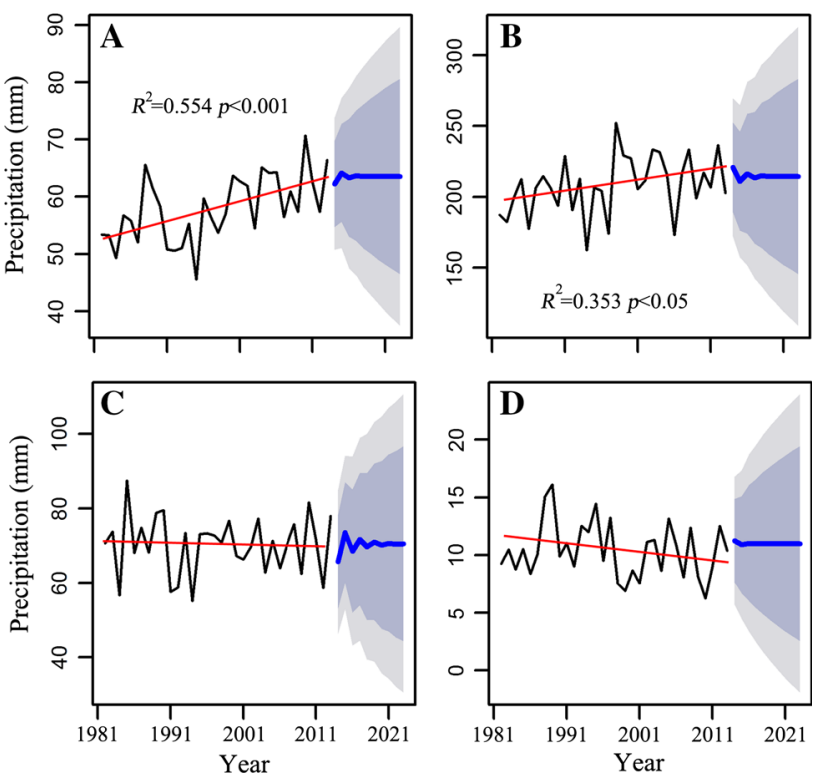

Fig. 6 Variations in precipitation on the Tibetan Plateau from 1982 to 2013. Graphs $\mathbf{a}, \mathbf{b}, \mathbf{c}$, and $\mathbf{d}$ represent variations of precipitation in spring, summer, autumn, and winter, respectively 


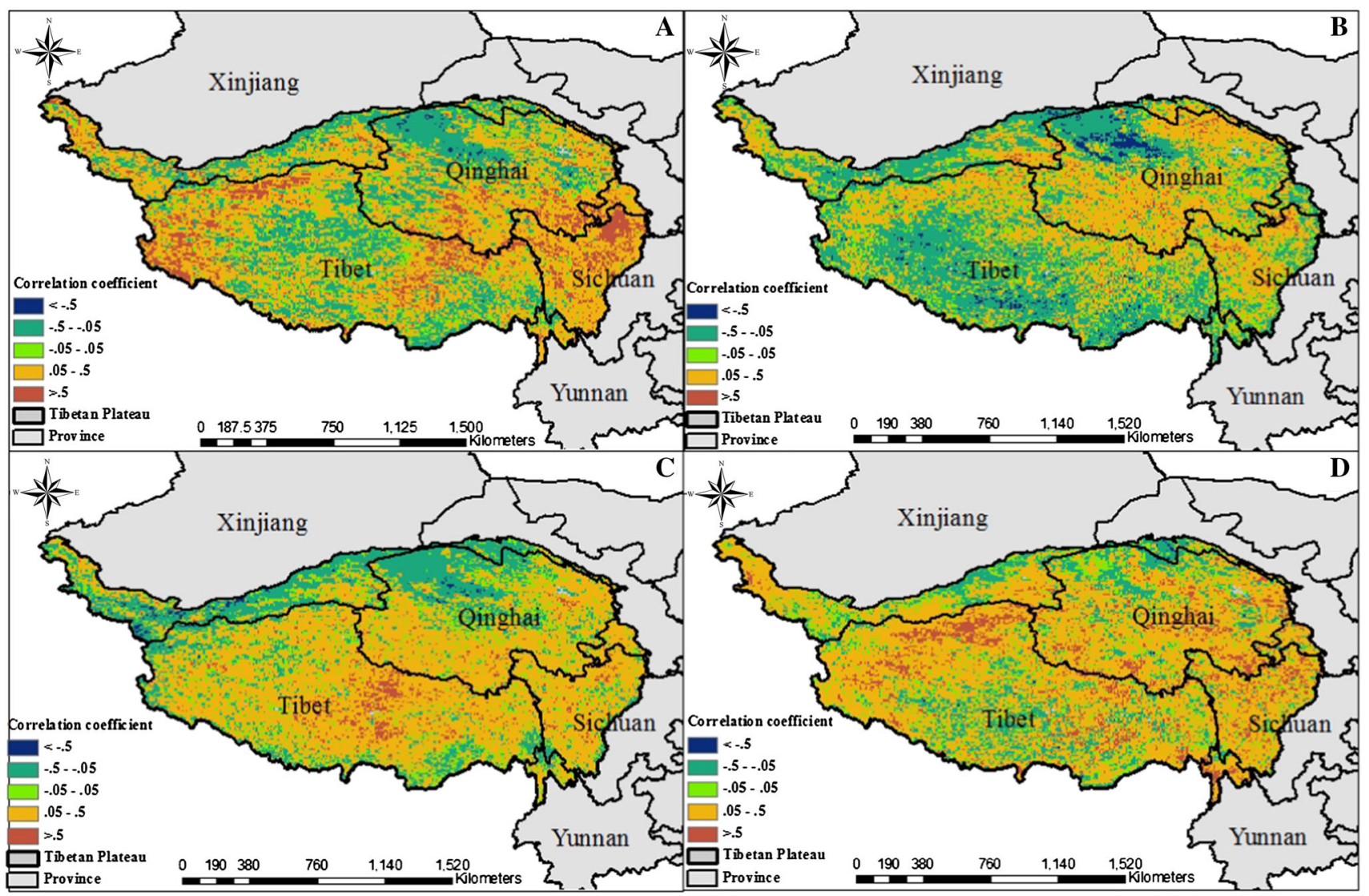

Fig. 7 Spatial distribution of correlation coefficient between NDVI and temperature on the Tibetan Plateau. Graphs a, b, $\mathbf{c}$, and $\mathbf{d}$ represent correlations in spring, summer, autumn, and winter, respectively

\section{Variations of temperature and precipitation}

There is no doubt that the climate in the Tibetan Plateau has been changed not only in time but also in space under the condition of global warming (Meng et al. 2011). The temperature has a significant creased trend, and there were certain minor fluctuations in precipitation (Wang et al. 2011). The mean temperature has been increased $0.64{ }^{\circ} \mathrm{C}$ per 10 years, with the biggest increment shown in the winter, although IPCC (2007) reported that the global mean land surface has warmed $0.27{ }^{\circ} \mathrm{C}$ per decade since 1979 . Our result is found not to be in line with the report of Potter and Brooks (1998); they suggested that mean temperatures had increased by $0.37-0.45{ }^{\circ} \mathrm{C}$ per 10 years between 1960 and 2005 on the Tibetan Plateau. Moreover, it is worth mentioning that the variation of precipitation was greater than the variation of temperature in each season, which may be due to changes in the monsoon system in East Asia (Wang et al. 2011).

\section{Effects of temperature and precipitation on seasonal NDVI}

The effect of seasonal accumulated precipitation on NDVI was stronger than seasonal mean temperature on it (Figs. 7,8). For Northern Tibet, a more negative than positive impact was produced by climate change on grassland net primary productivity (Revadekar et al. 2012). The regions affected by temperature and precipitation do not overlap in the same season; the reason for this may be the lagging of precipitation. Moreover, the impact of land-use activities on vegetation cannot be neglected (Ji and Peters 2004). Nevertheless, abrupt changes of climate elements at a small scale cannot directly cause abrupt changes of NDVI. Anomalies of NDVI were not found to be highly correlated with monthly climate data (Shen et al. 2014). In addition, over a longer time scale, the correlations of the average temperature determines the changes in NDVI; over a shorter time scale, changes in the magnitude of precipitation have a significant influence on NDVI (Wang 


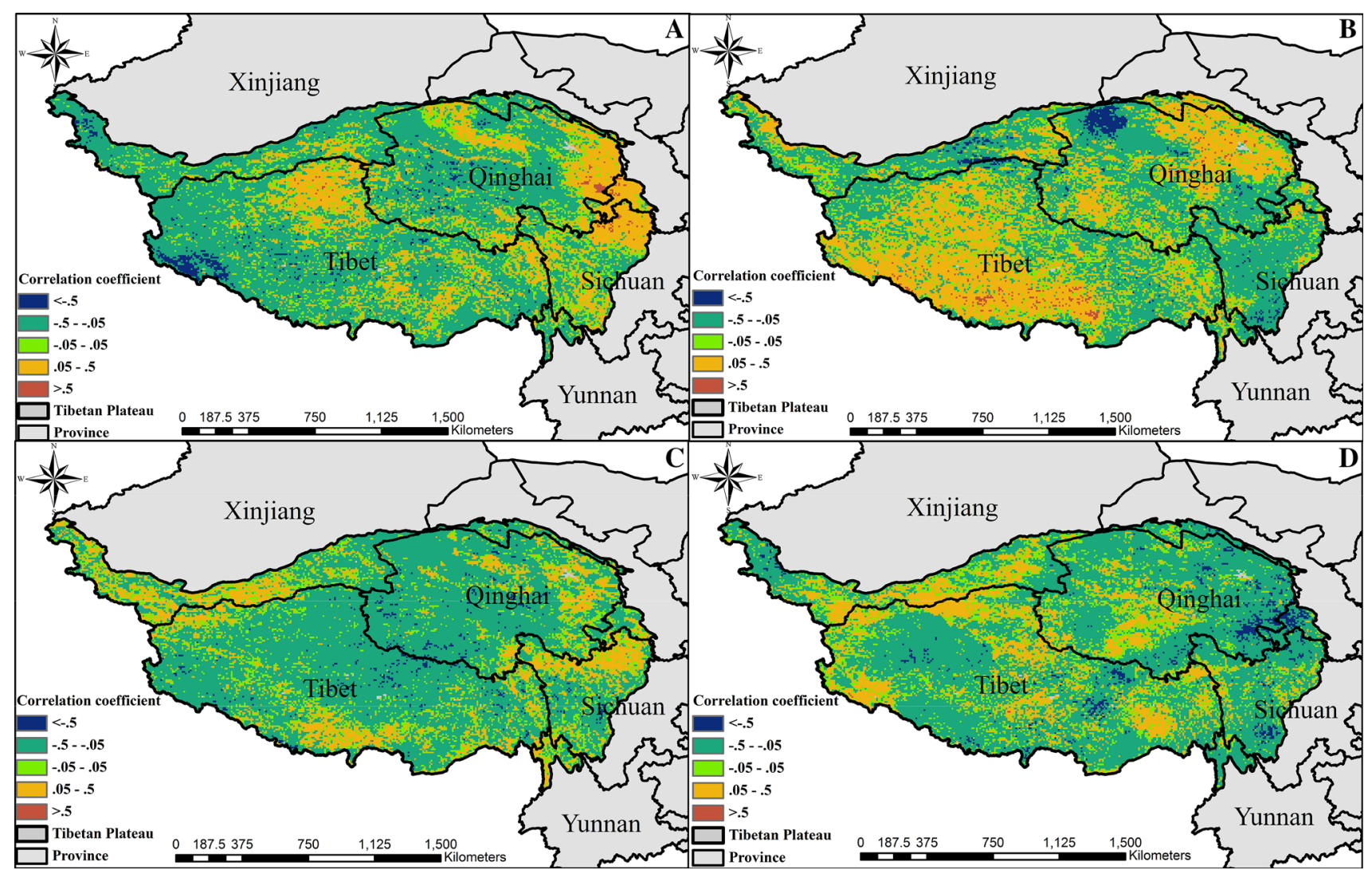

Fig. 8 Spatial distribution of correlation coefficient between NDVI and precipitation on the Tibetan Plateau. Graphs $\mathbf{a}, \mathbf{b}, \mathbf{c}$, and $\mathbf{d}$ represent correlations in spring, summer, autumn, and winter, respectively

et al. 2011). Owing to the fact that the Tibetan Plateau is located in a unique geographic environment with the characteristics of middle-low latitude, high altitude, and very low average air temperature (Meng et al. 2011), the variations of NDVI were mainly out of phase with the increasing air temperature (Liu et al. 2008). Vegetation was quite sensitive to precipitation in arid regions, and there is a negative correlation between the NDVI and temperature. In contrast, for regions with sufficient precipitation, temperature was the primary factor limiting vegetation growth, and the influence of precipitation on vegetation growth was less important (Shen et al. 2014). In addition, different types of vegetation may produce different sensitivities to climatic change (Piao et al. 2006). The seasonal NDVI of temperate desert steppe did not show significant correlation with the temperature in any season. Meanwhile, the correlation between NDVI and precipitation was notable and appeared to exhibit strong lag effects (Bao et al. 2014).

\section{Conclusions}

Based on the above analysis, we knew that the seasonal change trends of NDVI increased incrementally, except in the winter, across the Tibetan Plateau from 1982 to 2013.
Most of the regions were in an insignificant recovery situation, while the eastern and southern Tibetan Plateau appeared to experience significant recovery. In addition, the temperature and precipitation have gradually increased over time. Moreover, the influence of temperature and precipitation differed in different seasons across the Tibe$\tan$ Plateau. In the spring, the influence of temperature and precipitation were roughly the same on the Tibetan Plateau. The eastern Tibetan Plateau showed a significant positive correlation, but the western regions presented a negative correlation between NDVI and temperature in the summer. However, the regions appeared to have opposite relationships between NDVI and precipitation in comparison with the temperature in summer.

In short, this study demonstrates seasonal vegetation changes and emphasizes the important role of seasonal temperature and precipitation in controlling vegetation dynamics. Moreover, more analysis could be done in regards to the hysteresis between vegetation and climatic factors, especially precipitation.

Acknowledgments We wish to thank the China Meteorological Data Sharing Service System for providing meteorological data. This research was funded by the National Natural Science Foundation of China (No. 41501057), West Light Foundation of The Chinese 
Academy of Sciences and the Open Fund of the Key Laboratory of Mountain Surface Processes and Eco-regulation.

\section{References}

Bao G, Qin ZH, Bao YH, Zhou Y, Li WJ, Sanjjav A (2014) NDVIBased long-term vegetation dynamics and its response to climatic change in the Mongolian Plateau. Remote Sens 6(9):8337-8358

Chu D, Lu LX, Zhang TG (2007) Sensitivity of normalized difference vegetation index (NDVI) to seasonal and interannual climate conditions in the Lhasa area, Tibetan plateau. China. Arct Antarct Alp Res 39(4):635-641

Fan JW, Shao QQ, Liu JY, Wang JB, Harris W, Chen ZQ, Zhong HP, Xu XL, Liu GR (2010) Assessment of effects of climate change and grazing activity on grassland yield in the Three Rivers Headwaters Region of Qinghai-Tibet Plateau, China. Environ Monit Assess 170:571-584

Gao QZ, Li Y, Wan YF, Qin XB, Jiangcun WZ, Liu YH (2009) Dynamics of alpine grassland NPP and its response to climate change in Northern Tibet. Clim Chang 97(3-4):515-528

Gao QZ, Wan YF, Xu HM, Li Y, Jiangcun WZ, Borjigid A (2010) Alpine grassland degradation index and its response to recent climate variability in Northern Tibet, China. Quat Int 226(1-2):143-150

Gurgel HC, Ferreira NJ (2003) Annual and interannual variability of NDVI in Brazil and its connections with climate. Int J Remote Sens 24(18):3595-3609

IPCC (2007) Climate Change 2007: The physical science basis. Contribution of Working Group I to the Fourth Assessment Report of the IPCC (Cambridge University Press, Cambridge, UK)

Ji L, Peters AJ (2004) A spatial regression procedure for evaluating the relationship between AVHRR-NDVI and climate in the northern Great Plains. Int J Remote Sens 25:297-311

Liu XD, Chen BD (2000) Climatic warming in the Tibetan Plateau during recent decades. Int J Climatol 20:1729-1742

Liu W, Guo QH, Wang YX (2008) Temporal-spatial climate change in the last 35 years in Tibet and its geo-environmental consequences. Environ Geol 54:1747-1754

Meng M, Ni J, Zong MJ (2011) Impacts of changes in climate variability on regional vegetation in China: NDVI-based analysis from 1982 to 2000. Ecol Res 26:421-428

Peng JF, Gou XH, Chen FH, Fang KY (2010) Climate-growth relationships of Qilian juniper Sabina przewalskii in the Anyemaqen Mountains, Tibet. Clim Res 41:31-40

Piao SL, Mohammat A, Fang JY, Cai Q, Feng JM (2006) NDVIbased increase in growth of temperate grasslands and its responses to climate changes in China. Glob Environ Chang 16(4):340-348

Potter CS, Brooks V (1998) Global analysis of empirical relations between annual climate and seasonality of NDVI. Remote Sens 19:2921-2948

Revadekar JV, Tiwari YK, Kumar KR (2012) Impact of climate variability on NDVI over the Indian region during 1981-2010. Int J Remote Sens 33:7132-7150

Schultz PA, Halpert MS (1995) Global analysis of the relationships among a vegetation index, precipitation and land-surface temperature. Int J Remote Sens 16:2755-2777

Shen ZX, Fu G, Yu CQ, Sun W, Zhang XZ (2014) Relationship between the growing season maximum enhanced vegetation index and climatic factors on the Tibetan Plateau. Remote Sens 6(8):6765-6789

Sun R, Liu CM, Zhu QJ (2002) Dynamic change of net primary productivity and fractional vegetation cover in the Yellow River Basin using multi-temporal AVHRR NDVI Data. J Geogr Sci 12:29-34

Sun J, Cheng GW, Li WP, Sha YK, Yang YC (2013) On the variation of NDVI with the principal climatic elements in the Tibetan Plateau. Remote Sens 5(4):1894-1911

R Development Core Team (2011) R: A language and environment for statistical computing, R Foundation for Statistical Computing, Vienna, Austria, ISBN 3-900051-07-0, http://www.Rproject.org/. Accessed 20 May 2015

Walther GR, Post E, Convey P, Menzel A, Parmesan C, Beebee TJC, Fromentin JM, Hoegh-Guldberg O, Bairlein F (2002) Ecological responses to recent climate change. Nature 416(6879):389-395

Wang BL, French HM (1994) Climate controls and high-altitude permafrost, Qinghai-Xizang (Tibet) Plateau, China. Permafr Periglac 5:87-100

Wang GX, Wang YB, Li YS, Cheng HY (2007) Influences of alpine ecosystem responses to climatic change on soil properties on the Qinghai-Tibet Plateau, China. Catena 70(3):506-514

Wang J, Meng JJ, Cai YL (2008) Assessing vegetation dynamics impacted by climate change in the southwestern karst region of China with AVHRR NDVI and AVHRR NPP time-series. Environ Geol 54(6):1185-1195

Wang GX, Bai W, Li N, Hu HC (2011) Climate changes and its impact on tundra ecosystem in Qinghai-Tibet Plateau, China. Clim Chang 106:463-482

Xu XK, Chen H, Levy JK (2008) Spatiotemporal vegetation cover variations in the Qinghai-Tibet Plateau under global climate change. Chin Sci Bull 53:915-922 